\title{
Potential of an improved energy efficiency in the chassis
}

\author{
Andreas Schultze $^{1}$ (1) $\cdot$ Markus Lienkamp $^{1}$
}

Received: 2 December 2015/Accepted: 28 July 2016/Published online: 4 August 2016

(C) Springer International Publishing Switzerland 2016

\begin{abstract}
In this paper, an approach is presented to determine the losses of the different components in the chassis system. An enhanced two-track model is extended by sub-models to simulate losses and efficiencies. These sub-models are describing the loss behavior, which is compared to the state of art. The energy saving potential of each component is analyzed by optimizing the package of axle components and regarding technology improvements. The study is based on measured user behavior, which includes lateral and longitudinal dynamics as well as road unevenness.
\end{abstract}

Keywords Energy efficiency in chassis - Two-track model $\cdot$ Realistic driving data $\cdot$ Simulation of energy losses

\section{List of symbols}

$\begin{array}{ll}\alpha & \text { Side slip angle } \\ \alpha_{\mathrm{b}} & \text { Angle of brake pad position } \\ \alpha_{\mathrm{b}, \text { pad }} & \text { Angle of brake pad arc } \\ \beta & \text { Angle between drive shaft and } x-y \text {-plane } \\ \gamma & \text { Camber angle } \\ \delta & \text { Steering angle } \\ \eta & \text { Level of efficiency } \\ \eta_{\text {inner }} & \text { Level of efficiency of the constant velocity } \\ & \text { joint located at the gearbox }\end{array}$

WKM Symposium 2015, 23rd July-24th July 2015, Garching b. München, Germany.

Andreas Schultze

Schultze@ftm.mw.tum.de

Markus Lienkamp

Lienkamp@ftm.mw.tum.de

1 Institute of Automotive Technology, Technische Universität München, Garching b. Munich, Germany $\eta_{\text {outer }}$

$\eta_{\text {tripod }}$

$\eta_{\text {ball }}$

$\kappa$

$\mu_{\mathrm{L}}$

$\rho$

$\tau$

$\varphi$

$\omega$

$a_{\text {bearing }}$

$c$

$c_{\text {caliper }}$

$c_{\text {caliper+piston }}$

$c_{\text {piston }}$

$d$

$e$

$l_{\mathrm{sw}}$

$m$

$n$

$\vec{p}$

$\vec{q}$

$r_{\text {eff }}$

$r_{\text {stat }}$

$s_{\text {bearing }}$

$s_{\text {brake }}$

$s_{\text {in }}$
Level of efficiency of the constant velocity joint located at the wheel Level of efficiency of tripod joint Level of efficiency of ball joint Longitudinal tire slip Friction coefficient of wheel bearings Angle between drive shaft and $z-y$-plane Angle between $z$-axis and axis of torque acting on upright

Joint articulation angle of constant velocity joints

Angular velocity of a wheel

Distance between the pressure centres of the bearings

Center point of bearings

Translational stiffness of caliper sealing ring

Combined translational stiffness of caliper and piston sealing ring

Translational stiffness of piston sealing ring

Inner bearing diameter

Error

Length of the drive shaft

Mass

Rotational speed of drive shaft

Orientation vector of drive shaft

Orientation vector of wheel spin axis

Effective brake radius

Static loaded tire radius

Distance between wheel center and center of bearings

Distance between center of brake disk and center of bearings

Distance between $z$ '-axis and begin of contact between brake pad and disk 


\begin{tabular}{|c|c|}
\hline$s_{\text {mid }}$ & $\begin{array}{l}\text { Distance between } z^{\prime} \text {-axis and center of } \\
\text { contact between brake pad and disk }\end{array}$ \\
\hline$s_{\text {out }}$ & $\begin{array}{l}\text { Distance between } z \text {-axis and end of contact } \\
\text { between brake pad and disk }\end{array}$ \\
\hline$v_{y}$ & Velocity in lateral tire direction \\
\hline$v_{x}$ & Velocity longitudinal tire direction \\
\hline$x_{\text {wheel }}$ & $\begin{array}{l}\text { Distance between outer drive shaft joint and } \\
\text { gearbox output shaft in } x \text {-direction }\end{array}$ \\
\hline$y_{\text {wheel }}$ & $\begin{array}{l}\text { Distance between outer drive shaft joint and } \\
\text { gearbox output shaft in } y \text {-direction }\end{array}$ \\
\hline$z_{\text {wheel }}$ & $\begin{array}{l}\text { Distance between outer drive shaft joint and } \\
\text { gearbox output shaft in } z \text {-direction }\end{array}$ \\
\hline$\dot{z}_{\text {damper }}$ & Velocity of wheel damper \\
\hline$F_{\mathrm{b}}$ & Brake pad force \\
\hline$F_{\text {damper }}$ & Force of wheel damper \\
\hline$F_{r 1 / 2}$ & Radial force on wheel bearing \\
\hline$F_{a 1 / 2}$ & Axial force on wheel bearing \\
\hline$F_{X}$ & Longitudinal tire force \\
\hline$F_{Y}$ & Lateral tire force \\
\hline$F_{Z}$ & Vertical tire force \\
\hline$L$ & Load of wheel bearing \\
\hline$P_{\text {damper }}$ & Power loss of wheel dampers \\
\hline$P_{\text {tire,camber }}$ & Power loss due to camber change \\
\hline$P_{\text {tire,roll }}$ & Power loss due to rolling resistance \\
\hline$P_{\text {tire,toe }}$ & Power loss due to change of steering angle \\
\hline$P_{\text {tire }, x}$ & Power loss due to longitudinal tire slip \\
\hline$P_{\text {tire }, y}$ & Power loss due to lateral tire slip \\
\hline$T$ & Drive torque at gearbox outlet \\
\hline$T_{\text {loss, driveshaft }}$ & Loss torque of drive shaft with both joints \\
\hline$T_{\mathrm{rbt}}$ & Residual brake torque \\
\hline$T_{\text {res }}$ & Torque acting on upright \\
\hline$T_{\mathrm{R}}$ & Drag torque of a wheel bearing \\
\hline$T_{\text {wheel }}$ & Torque at wheel \\
\hline$T_{X}$ & Overturning moment \\
\hline$T_{Y}$ & Rolling resistance torque \\
\hline$T_{Z}$ & Self-aligning torque \\
\hline
\end{tabular}

\section{Introduction}

\subsection{Problem}

Difficulties in energy storage of alternative drivetrain technologies and $\mathrm{CO}_{2}$-emission regulations for conventional vehicles require the improvement of the entire vehicle efficiency. Reducing vehicle energy consumption has been a focus in car development in the past years. Therefore, most high impact and/or low cost measures have already been put into practice, like e.g., the widespread use of electric power steering.

This leads to the analysis of the other effects responsible for driving resistances. Most of them seemed to have a too small energy saving potential so far. Some of the lower potentials were too costly to use in the past as well. One of these systems is the chassis. In a first step, the losses and potentials have to be quantified. In a second step, systems can be developed to exploit the potentials.

\subsection{Literature}

To reduce vehicle energy consumption, regarding the whole chassis, [1] sees a potential of 5-10 $\mathrm{g} \mathrm{CO}_{2} / \mathrm{km}$, without mentioning how these values are achieved. Using a $\mathrm{CO}_{2}$ equivalent of $80 \mathrm{~g} \mathrm{CO}_{2} / \mathrm{MJ}$ [2], in terms of vehicle consumption, a more comparable potential of $17-35 \mathrm{Wh} /$ $\mathrm{km}$ can be calculated.

Several contributions make general statements indicating the percentage of energy consumption caused by the chassis. As a comparatively detailed example, [3] mentions a percentage of 12-15\% for energy losses in chassis systems and $58 \%$ for the conventional drivetrain. Regarding a doubled level of efficiency for electrical drivetrains, the chassis losses can be calculated to 17-21\%. The underlying assumptions, like the driving profile are mostly not provided or in most cases only longitudinal dynamics are considered.

A high number of potential analyses for improved energy efficiency and loss energies can be found for many components of the chassis (e.g. [3]). These studies often make use of special assumptions and cannot be compared with another, as they are not conducted on the same basis of vehicle parameters and driving inputs. Therefore, it seems necessary to examine those effects using a comparable basis.

\section{Method}

We present an approach for this to analyze the loss of energy and the potentials for improved energy efficiency for the entire chassis. The system boundaries are road, all connection points between axle and structure, outputs of the differential and steering wheel.

The analysis is based on an enhanced non-linear twotrack model which includes longitudinal, lateral, and vertical degrees of freedom as well as all rotating movements. It is extended with kinematics and compliance. There are several loss calculations implemented, partly with influence on vehicle behavior. Those models follow the approach of being as simple as possible. A controller allows to simulate given tracks with the model. This enables the usage of realistic driving behavior. Knowing the energy losses of the chassis resulting from the simulation model, the energy saving potential can be estimated. 


\section{Method}

\subsection{Two-track model}

To get the same basis for the components' analysis, it is necessary to map the overall vehicle behavior. Therefore, a two-track model has been selected. It was preferred to multibody simulation for its lower calculation time and parametrization effort. A single-track model is not used as it is not able to model kinematics or dampers sufficiently.

The vehicle model is built in a modular way, so it can be used in simple 2D or more complex 3D simulations. This paper shows the complex model setup, which includes 22 degrees of freedom (Fig. 1). The equations calculating acceleration, yaw rate and side slip angle are based on [4]. They were extended by the influence of aerodynamic forces acting directly on the three equations describing the structure's behavior. Using the actual vertical coordinates of the track the road gradient and bank angle are calculated to model the road. This calculation is used for modeling the influence on the vehicle accelerations defined in a chassisfixed coordinate system.

The vehicle's roll and pitch movements are modeled by applying the law of conservation of angular momentum. The equation is influenced by 2D-accelerations and all spring, damper and anti-roll bar forces. The acting forces are split up. Anti-squat, anti-dive and anti-roll support are considered by a constant location of roll and pitch axes. The outputs of these calculations are angular movements, forces acting on the wheel by kinematic coherences, and vertical wheel travel. Vertical dynamics of the body are determined in parallel. In this case, the body is assumed to be a point mass. The forces of springs and dampers as well as aerodynamic lift, gravitation, and vertical acceleration achieve an equilibrium. As a result, the vertical movement of the body and all proportional vertical wheel travels are issued.
The vertical wheel travel outputs are used to calculate the spring and damper forces acting on wheel and body. Wheel travel is also used to obtain toe-in and camber angles based on kinematic characteristic curves. Compliance is introduced in the same way, but needs tire lateral and longitudinal forces as input. These simplifications were made for easier parametrization and better variation possibilities.

In the 'wheel and tire' model the vertical wheel movement is calculated including road input, tire spring, and damping parameters as well as the formerly generated wheel suspension forces. The principle of angular momentum used for the wheels makes it possible to calculate angular velocities based on forces and moments acting from tires, brakes, and drivetrain.

The wheel alignment is summed up with the steering angles, which are calculated by steering wheel input via a wheel individual steering ratio characteristics curve. All speeds and forces described above are used as an input for the tire model, where a Pacejka MF Tire model [5] is used. To represent the transient tire behavior via relaxation lengths, the linear model implementation was selected with a damping factor at low speeds varied by the longitudinal velocity.

In this paper, the parameter set for the Visio.M electric research vehicle was used [6]. Parameters (Table 1) were deduced of different measurements on test benches allowing us to determine kinematics and compliance, damper characteristics, aerodynamics or drivetrain efficiencies. Missing data were assumed to be identical to the construction data. The model was verified to driving data and multibody simulations. Therefore, the objective maneuvers 'Constant Radius Cornering' [7] at a radius of $r=40 \mathrm{~m}$ and 'Step Steer' [8] at a velocity of $v=80 \mathrm{~km} / \mathrm{h}$ were used. The principal characteristics of the model correspond to the compared data, however, absolute values are

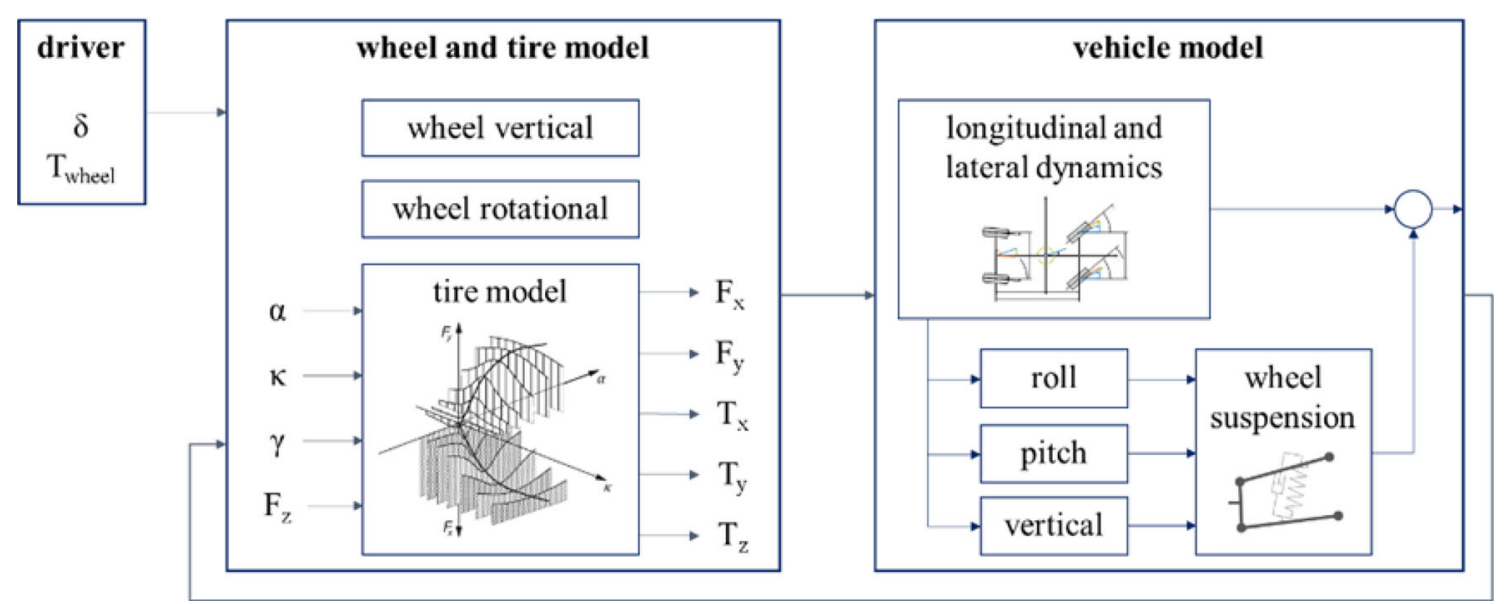

Fig. 1 Outline of the two-track model 
Table 1 Main parameters of the two track model

\begin{tabular}{llll}
\hline Parameter & Value & Description & Source \\
\hline$m$ & $753.5 \mathrm{~kg}$ & Mass & Measurement \\
$I_{z}$ & $717 \mathrm{~kg} / \mathrm{m}^{2}$ & Moment of inertia (yaw) & Measurement \\
$x_{\mathrm{SP}}$ & $1.182 \mathrm{~m}$ & Distance between center of gravity and front axle & Measurement \\
$z_{\mathrm{SP}}$ & $0.462 \mathrm{~m}$ & Distance between ground and center of gravity & Measurement \\
$l$ & $2.100 \mathrm{~m}$ & Wheel base & Construction data \\
$s_{\mathrm{F}}$ & $1.367 \mathrm{~m}$ & Track width front & Construction data \\
$s_{\mathrm{R}}$ & $1.426 \mathrm{~m}$ & Track width rear & Construction data \\
$c_{\mathrm{SF}}$ & $6229 \mathrm{~N} / \mathrm{m}$ & Spring rate at front wheel & Construction data \\
$c_{\mathrm{SR}}$ & $11,951 \mathrm{~N} / \mathrm{m}$ & Spring rate at rear wheel & Construction data \\
$d_{\mathrm{dF} / \mathrm{R} \text { comp }}$ & $1060 \mathrm{Ns} / \mathrm{m}$ & Compression damping rate & Construction data \\
$d_{\mathrm{dF} / \mathrm{R} \text { reb }}$ & $1260 \mathrm{Ns} / \mathrm{m}$ & Rebound damping rate & Construction data \\
$c_{\text {arbF }}$ & $30 \mathrm{kN} / \mathrm{m}$ & Anti-roll-bar rate based on vertical wheel travel difference & Construction data \\
$c_{x}$ & 0.24 & Aerodynamic drag coefficient & Measurement \\
$A_{\text {front }}$ & $1.69 \mathrm{~m}{ }^{2}$ & Frontal area & Construction data \\
Tire data & Pacejka parameters & Tire model for the corresponding tire (115/70R16) & Tire model based on measurements \\
\hline
\end{tabular}

not matching due to the missing measurements of some parameters.

\subsection{Calculation of energy losses}

\subsubsection{Limitations}

In the following, calculation methods of energy losses are presented. The described models are limited to stationary temperatures. Their values correspond to normal operating temperatures.

\subsubsection{Tires}

In addition to the modeling of vehicle behavior, the energy losses are calculated for the different components. Energy losses caused by the tires are split up. The lateral slip loss is represented using the validated approach postulated by [9] and [10]:

$P_{\text {tire }, y}=v_{y} \cdot F_{y}$,

$v_{y}$ is the lateral velocity and $F_{y}$ the lateral force in the tire coordinate system located in the contact patch (TYDEX W [11]). Power loss through longitudinal slip is calculated similarly to [12] as follows:

$P_{\text {tire }, x}=F_{x} \cdot v_{x} \cdot \kappa$.

The most significant energy losses are expected to be caused by the tires' rolling resistance. The underlying rolling resistance moment $T_{y}$ is an output of the tire model and is multiplied with the wheel speed $\omega$ :
$P_{\text {tire,roll }}=T_{y} \cdot \omega$.

The tire is subject to two additional rotational degrees of freedom resulting in inclination and toe-in movements. The respecting energy losses are calculated in the same way as the rolling resistance.

$P_{\text {tire,camber }}=T_{x} \cdot \dot{\gamma}$,

$P_{\text {tire,toe }}=T_{z} \cdot \dot{\delta}$.

Another loss factor is tire damping, which is not implemented yet due to the limited parametrization of the tire model used, but which is assumed to be negligible. A temperature dependency of the influencing parameters of the tire is neglected as well.

\subsubsection{Dampers}

Wheel dampers' energy dissipation is taken into account by applying following basic physical law:

$P_{\text {damper }}=F_{\text {damper }} \cdot \dot{z}_{\text {damper }}$.

The damping force is only dependent on speed. Friction influences are low and therefore neglected in this step and may be included in future investigations.

\subsubsection{Wheel bearings}

The model for wheel bearing friction is limited to angular contact ball bearings, as these are commonly used for wheel bearings. Their energy losses depend on different friction effects, which can be summarized in one 
coefficient [13] $\mu_{L}$ and lead to the following calculation of the drag torque $T_{R}$ :

$T_{R}=\mu_{L} \cdot L \cdot \frac{d}{2}$.

The linear approach to calculate the bearings friction causes an error of approximately 5-10\% compared to the more sophisticated calculation described in [13] or the operating range of a wheel bearing. This complex friction calculation is not used due to its high amount of parameters.

Parameter $\mathrm{d}$ describes the inner diameter of the bearing. The force distribution is shown in Fig. 2. The vertical load's shift in $x$-direction can be neglected for its only influence on the wheel rotation. This rotation does not affect the bearing load. Equations for radial and axial bearing forces can be derived by the equilibrium of forces and moments around point ' $c$ ' in Fig. 2. This simplification is possible by the linear approach of the friction calculations.

To calculate the friction, it is essential to know the bearing load. The load calculation follows the equations mentioned in [13]. Relevant bearing parameters were determined according to bearings with similar dimensions as installed in the prototype car.

There are different forces acting on tire and brake, which are relevant to calculate the radial loads of the wheel bearings (Fig. 2). They result from the tire model and brake torque. Applying the equilibrium of moments in point ' $c$ ', around the ' $x$ ' (8) and ' $z$ ' axis (9) with respect to the equilibrium of forces allow to calculate the radial bearing 1 and 2 loads according to (10).

$$
\begin{aligned}
& \sum T_{x}=0=\left(F_{y} \cdot \cos (\gamma)-F_{Z} \cdot \sin (\gamma)\right) \cdot r_{\text {stat }} \\
& \quad+\left(F_{z} \cdot \cos (\gamma)+F_{y} \cdot \sin (\gamma)\right) \cdot s_{\text {bearing }} \\
& +F_{b, z} \cdot s_{\text {brake }}+F_{\mathrm{r} 1, z} \cdot \frac{a_{\text {bear. }}}{2}-F_{r 2, z} \cdot \frac{a_{\text {bear. }}}{2}+T_{x, \text { tire }}, \\
& \sum \\
& \quad T_{z}=0=-F_{x} \cdot s_{\text {bearing }}-F_{b, x} \cdot s_{\text {brake }}-F_{r 1, x} \\
& \cdot \frac{a_{\text {bearing }}}{2}+F_{r 2, x} \cdot \frac{a_{\text {bearing }}}{2}+T_{z, \text { tire }}, \\
& F_{r i}=\sqrt{F_{r i, z}^{2}+F_{r i, x}^{2}} \quad(i=1,2) .
\end{aligned}
$$

\subsubsection{Drive shafts}

Constant velocity joints are commonly used for automotive drive shafts. In particular, ball joints on both ends for steered wheels and tripod joints for the use at the inboard end of the car are popular. For this reason, the described efficiency model only considers these two types.

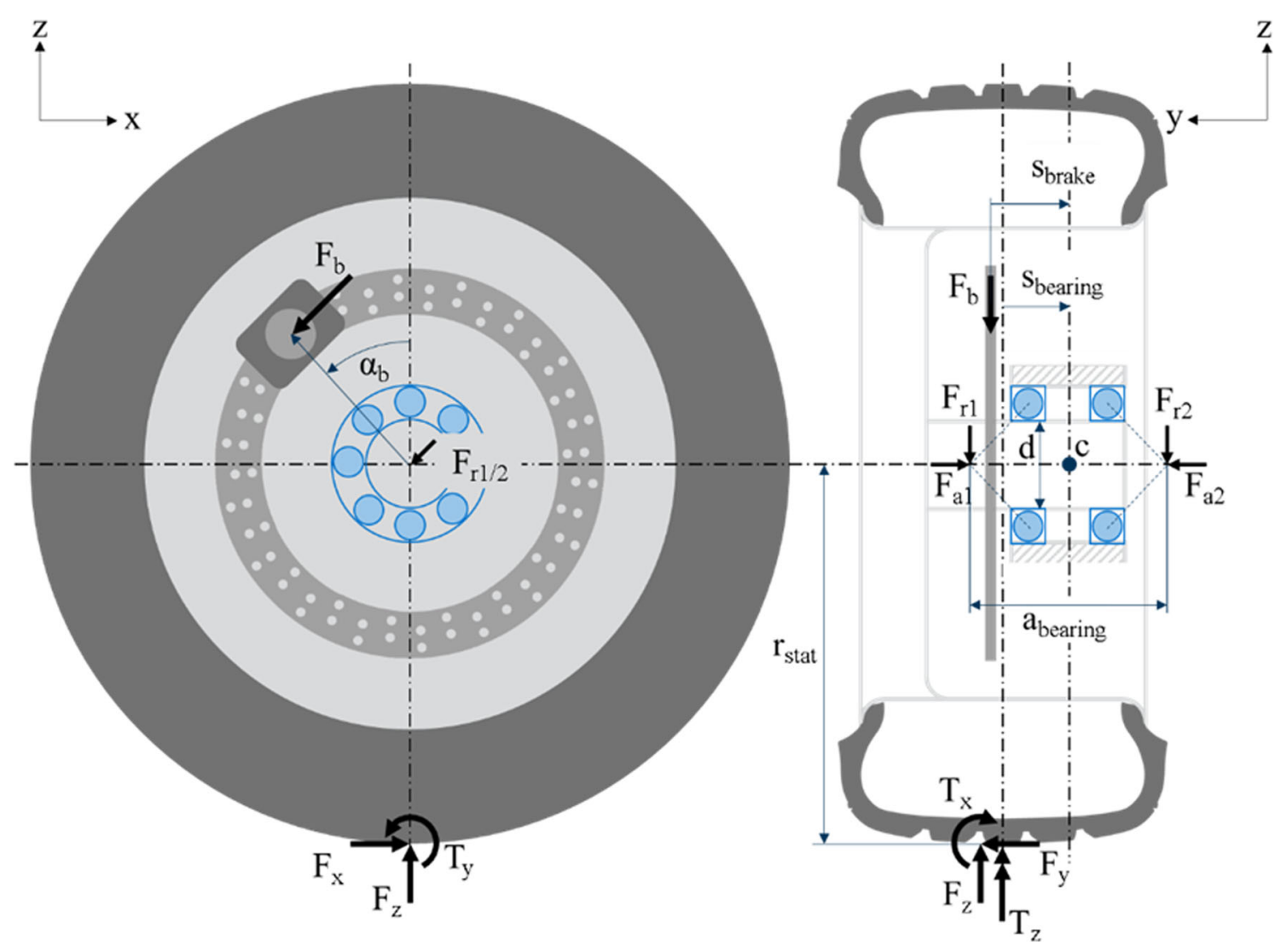

Fig. 2 Simplified relevant forces at the wheel 
Due to the function of the joints the two friction effects rolling and sliding occur. The level of efficiency mainly depends on the transmitted torque, the actual rotational speed and the deflection angle [14]. Drive torque and wheel speeds are given by the vehicle model. In contrast, the joints' articulation angles are determined by the described energy loss model. Other factors like lubrication conditions or temperature influence are neglected due to their complex quantification and low effect on the vehicles' energy consumption.

While the wheel position is changing during vehicle movement, the position of the output of the differential is assumed to be fixed. Thanks to the high stiffness of the drivetrain rubber bearings, the movement of the gearbox is negligible. Typically, there is an offset between the differential output axis and the joint at the wheel. The ycoordinate is made variable via the plunge travel of the tripod joint. The offsets in the $x$ - and $z$-axis ( $x_{\text {wheelo }}$ and $z_{\text {wheel0 }}$ ) cause additional angles $\beta_{0}$ and $\rho_{0}$. Figure 3 shows the angles and vectors used for the calculation of the outer joint's articulation angle. The coordinate system has the same orientation as the vehicle-fixed one and is located at the fulcrum of the outer joint. Vector $\vec{p}$ (11) describes the orientation of the drive shaft, vector $\vec{q}$ (12) represents the wheel bearing. The scalar product of (11) and (12) allow the calculation of the joint articulation angle.

$\vec{p}=\left(\begin{array}{c}\sin (\rho) \cdot \cos (\beta) \\ -\cos (\rho) \cdot \cos (\beta) \\ -\sin (\beta)\end{array}\right) \cdot l_{\mathrm{sw}}=\left(\begin{array}{c}x_{\text {wheel } 0}+x_{\text {wheel }} \\ y_{\text {wheel } 0}+y_{\text {wheel }} \\ z_{\text {wheel0 }}+z_{\text {wheel }}\end{array}\right)$,

$\vec{q}=\left(\begin{array}{c}\sin (-\delta) \cdot \cos (\gamma) \\ \cos (\delta) \cdot \cos (\gamma) \\ \sin (\gamma)\end{array}\right)$

Having determined all variables, it is possible to derive the level of efficiency of the drive shaft. [14] analyzed different types of fixed Rzeppa and sliding Tripod joints with respect to their energy losses. As a result, an area of level of efficiency is presented. The model described here uses a mean value of the described results (Fig. 4) at the

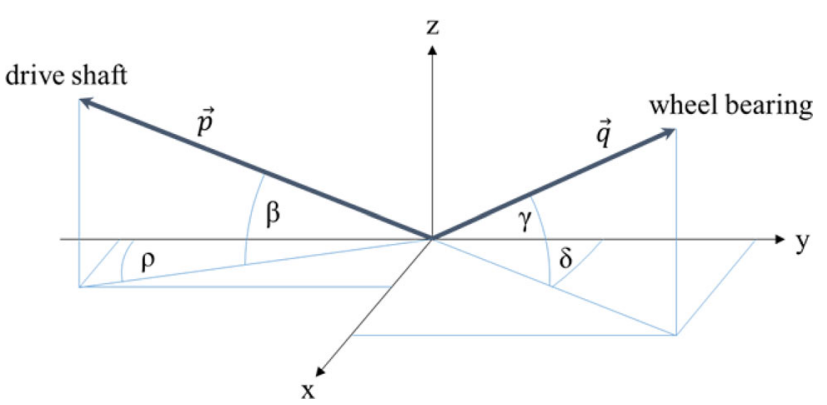

Fig. 3 Angles at the outer drive shaft joint operating point of $T_{0}=500 \mathrm{Nm}$ and $n_{0}=500 \mathrm{rpm}$. It is assumed that sliding ball joints have a similar level of efficiency as fixed ones.

Variations of rotational speed and torque are realized by a parallel shift of the described characteristic efficiency curves for tripod and ball joints. The dependency on torque and speed was analyzed in [14] at a joint articulation angle of $\varphi=7^{\circ}$. The maximum error of this simplification is approximately $e<0.11 \%$ for the ball joint and $e<0.07 \%$ for the tripod type. The calculated variation is limited to the extent of the underlying measurements. The empirical Eqs. (13) and (14) require torque values measured in $\mathrm{Nm}$ and wheel speed values measured in revolutions per minute, without using the units for calculation.

$$
\begin{aligned}
\eta_{\text {tripod }}(n, T)= & \left(\eta_{\text {tripod }}\left(n_{0}, T_{0}\right)-\left(1.45 \cdot\left(n-n_{0}\right)\right.\right. \\
& \left.\left.+2.36 \cdot\left(T-T_{0}\right)\right) \cdot 10^{-4}\right) \\
\eta_{\text {ball }}(n, T)= & \left(\eta_{\text {ball }}\left(n_{0}, T_{0}\right)-\left(3.30 \cdot\left(n-n_{0}\right)\right.\right. \\
+ & \left.\left.3.38 \cdot\left(T-T_{0}\right)\right) \cdot 10^{-4}\right) .
\end{aligned}
$$

The knowledge of the level of efficiency is sufficient to evaluate the primary energy losses. Through a higher drive torque demands, secondary effects can occur in the vehicle consumption. Therefore, the level of efficiency's influence on the drive torque has to be applied to the vehicle dynamics model. To obtain this variable, the levels of efficiency are switched in-line and calculated with the drive torque as follows:

$T_{\text {loss,driveshaft }}=T \cdot\left(1-\eta_{\text {inner }} \cdot \eta_{\text {outer }}\right)$.

\subsubsection{Brake caliper drag}

Brake caliper drag is an unintended friction torque occurring in the off-brake phase. This effect is caused by position tolerances and lateral run-out of wheel bearing and flange as well as the brake disk itself. Also, disk thickness variations induce points of contact between the disk and the pad. The influences of wheel hub elasticity, wheel bearing,

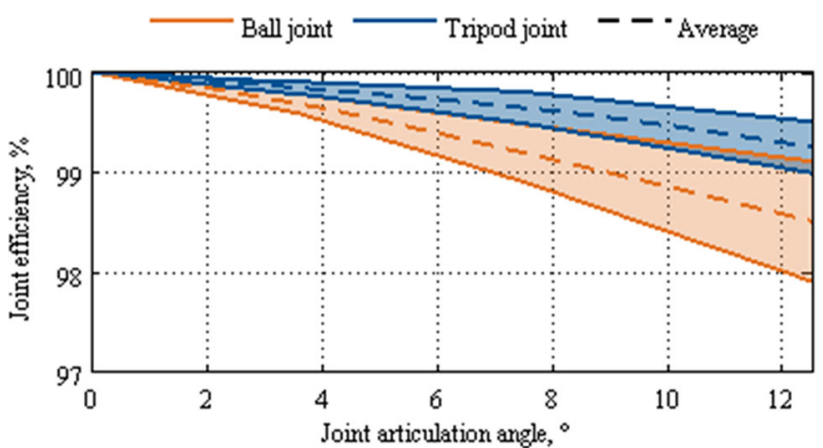

Fig. 4 Levels of efficiency for different constant velocity joints reg. [14] 
and flange cause additional offsets leading to torque drag. The brake caliper drag is also influenced by constructive parameters such as stiffness, friction coefficients of sliding parts, and the amount of play between disk and pad. Previous brake phases are influencing the position of the brake pads and subsequently the play. Many parameters are calculate an overlap. The model includes the disk's run-out and thickness variations as well as wheel bearing deformations and flange due to forces acting on the wheel. The relevant torque, determined similarly to the calculation described to obtain the bearing forces (16), acts on a linear torsional stiffness.

$\overrightarrow{T_{\text {res }}}=\left(\begin{array}{c}\left(F_{y} \cdot \cos (\gamma)-F_{z} \cdot \sin (\gamma)\right) \cdot r_{\text {stat }}+\left(F_{z} \cdot \cos (\gamma)+F_{y} \cdot \sin (\gamma)\right) \cdot s_{\text {bear. }}+T_{x} \\ 0 \\ -F_{x} \cdot s_{\text {bear. }}+T_{z}\end{array}\right)$.

changing over the lifetime of a brake resulting in a constant change of brake caliper drag. These aging effects are not considered in this paper. The described model is limited to disk brakes with sliding calipers as this is the most common type of wheel brakes [15]. They are also used in the Visio.M.

First of all, the degrees of freedom of the caliper and pad are analyzed (Fig. 5). The caliper housing slides on the guideway thanks to an elastic ring. An elastic seal ring enables sliding of the piston in the caliper housing. Before a translational movement occurs, the sealing is deformed elastically until the force exceeds the friction between the sealing and housing. The brake pad guideway is not considered as the friction is very low compared to the other effects.

Due to the distinct higher stiffness of the brake disk compared to the elasticities at the caliper, the disk is assumed to be rigid. With the actual play between disk and brake pads on each side and the lateral position variations of the disk at the effective brake radius, it is possible to

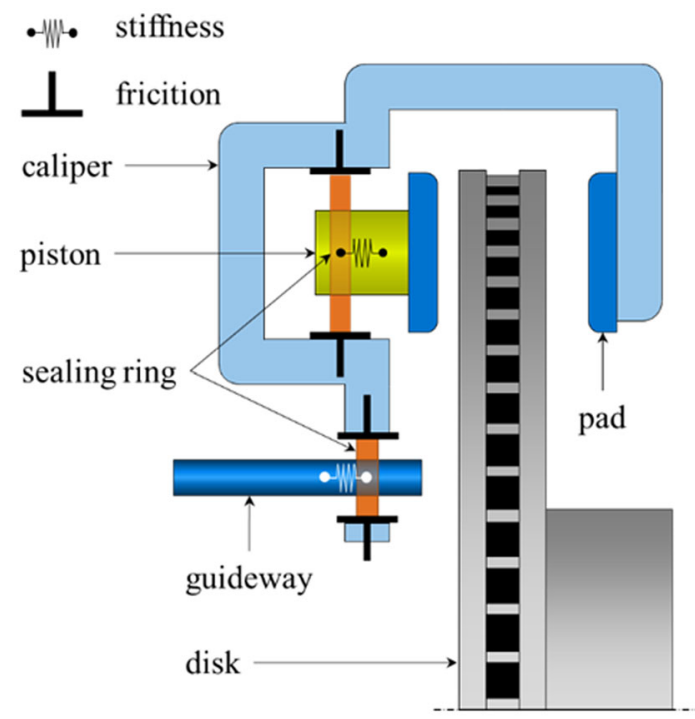

Fig. 5 Model concept for sliding caliper
Knowing the magnitude and orientation of the torque, it is possible to calculate the offsets of the brake disk to the pad (Fig. 6). The contact of pad and disk is discretized into three areas (feeding side, mid of contact, and out-run) to decrease the calculation effort. The offsets defined as ' $s$ ' describe the distance between the torque axis and the contact points. The calculation of the deformation angle allows to determine an additional virtual run-out at the contact points.

To determine a residual brake torque, a transfer function was implemented. It is derived of the sealing ring stiffness and friction forces, which are assumed to be of coulomb type. The resulting function is shown in Fig. 7. At zero overlap, the caliper and piston sealing rings are deformed in a reversible way. If the maximum friction force exceeds the pressure on the pad, the torque stays constant. When the movement reaches the end stop, a further torque increase is caused by the piston sealing stiffness. Once the piston end stop is reached, the housing stiffness has to be taken into account. The curve of the finger side follows equivalent effects.

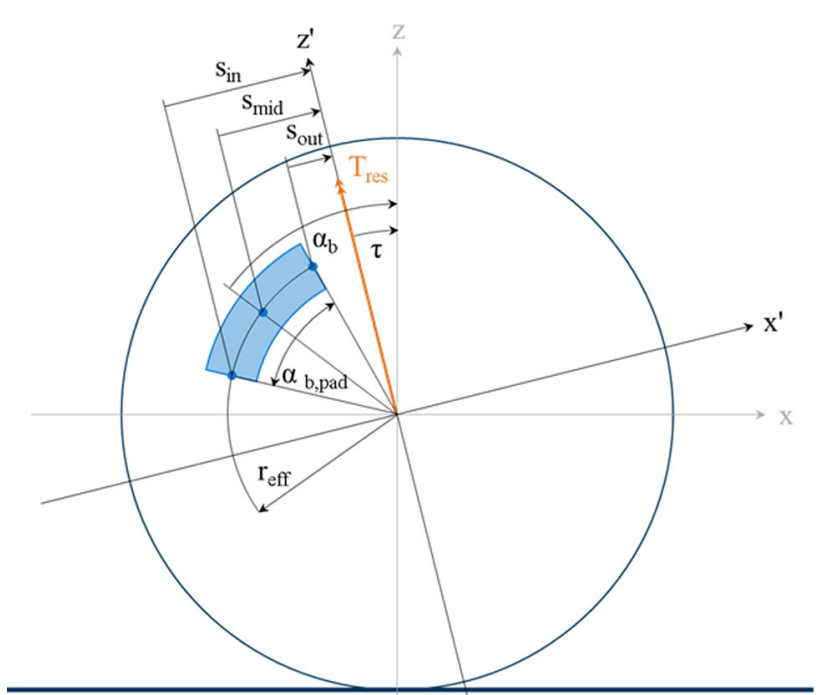

Fig. 6 Model concept for sliding caliper 
Fig. 7 Transfer function overlap to residual torque

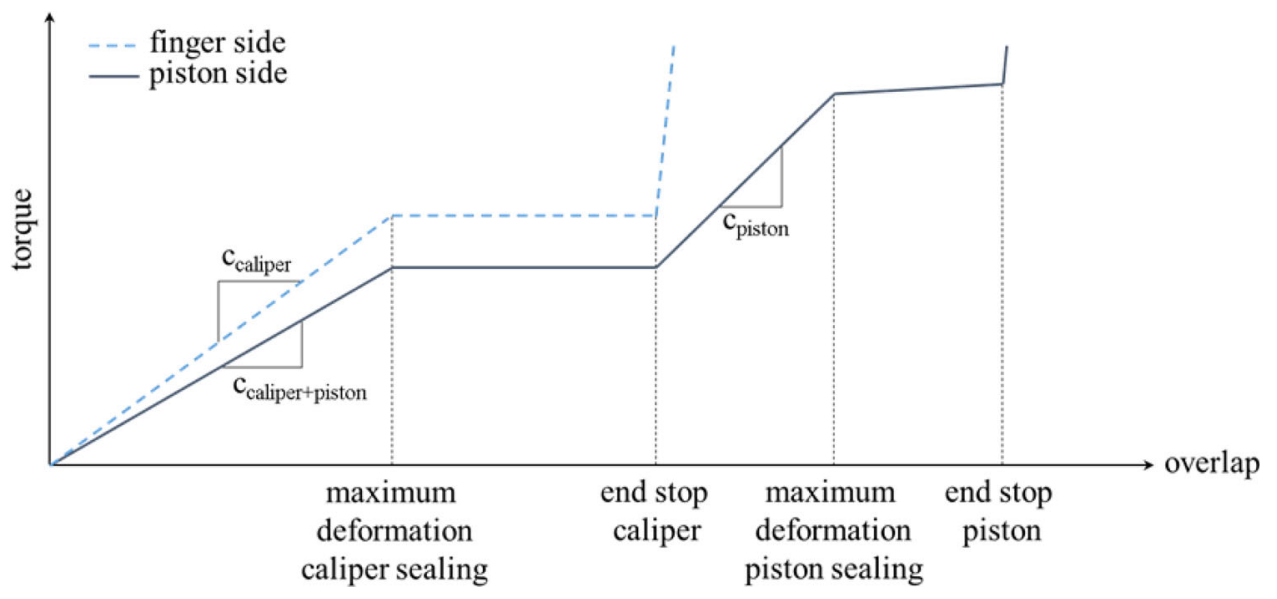

Overlaps exceeding the maximum for elastic deformations of the caliper sealing lead to caliper movement. This is realized by modifying the play between pad and disk on both sides. The piston's movement also results in a change of the play between pad and disk.

Lateral accelerations act on components and influence the residual torque. This effect can also influence the play between pad and disk in case of shifting caliper and piston. The inertia force of the brake pads leads to an additional residual torque of $\Delta T_{\mathrm{rbt}}=0.08 \mathrm{Nm}$ at the maximum lateral acceleration of the applicable car. Compared to the results of [16] at this lateral acceleration, the error is $<1 \%$. The force caused by the caliper mass itself leads to an additional torque of $\Delta T_{\mathrm{rbt}}=0.2 \mathrm{Nm}$. These effects are neglected at the described first step of this model.

Actuation of the brake system can influence the play and therefore the residual torque. The brake torque is used to calculate the resulting force acting on the piston. If this force exceeds the friction force of the sealing ring, the play is taken into account in the model.

The parameters of the brake caliper drag model are based on construction data or fitted to meet the state of art's amount of residual brake torque for the Visio.M car. Table 2 shows the resulting values of the transfer function.

For verification purposes the model parameters are set to the brake parameters provided in [16]. Figure 8 shows the

Table 2 Values of transfer function for the residual brake torque model

\begin{tabular}{ll}
\hline Parameter & Value \\
\hline Maximum deformation caliper sealing & $127 \mu \mathrm{m}$ \\
Torque at maximum deformation caliper sealing & $0.95 \mathrm{Nm}$ \\
End stop caliper & $1 \mathrm{~mm}$ \\
Maximum deformation piston sealing & $1228 \mu \mathrm{m}$ \\
Torque at maximum deformation piston sealing & $10.63 \mathrm{Nm}$ \\
End stop piston & $6228 \mu \mathrm{m}$ \\
\hline
\end{tabular}

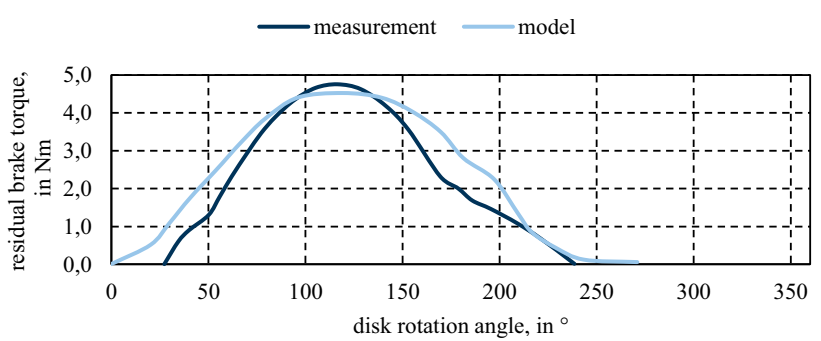

Fig. 8 Comparison of residual brake torque (model vs. measurements of [16]) for one disk rotation

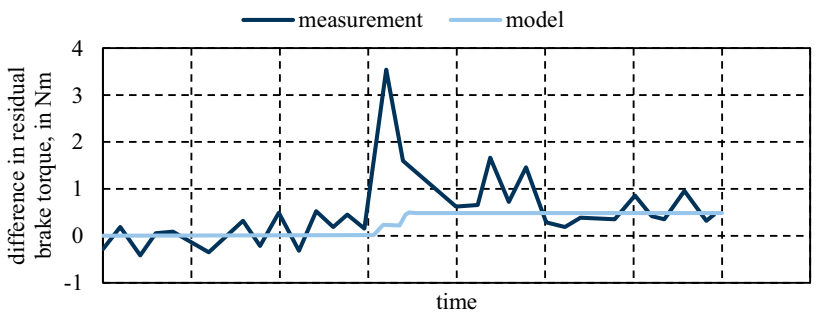

Fig. 9 Comparison of change in residual brake torque (model vs. measurements of [16]) after application of brake pressure

residual brake torque for one disk rotation. The model shows a similar behavior, especially when considering the peak and asymmetry between in-run and out-run of the brake pad. Figure 9 shows the increase of residual brake torque when brake pressures are applied. The results are similar to the literature's measurements.

\subsubsection{Power steering}

Electric power steering is state of the art and will achieve a market share in 2020 comparable to hydraulic power steering systems in the past [17]. Therefore, the described method is limited to this type of power steering. Due to the support of every steering action, electrical power is used and energy losses occur. In the model, it is possible to simulate this effect. However, it is not described in this 
paper as the Visio.M does not have any steering support. This is possible thanks to its low weight and the resulting self-aligning moment.

\subsection{Driving data}

The modeled friction effects depend on forces and driving states. This requires a closer look on consumer relevant vehicle behavior. The energy saving potentials are only relevant in commonly used driving states. Driving data were recorded thanks to the use of two equipped vehicles (BMW i3 and VW e-up!) with inertial and GPS navigations systems of type OxTS RT2500. These vehicle models were available as test vehicles and only were used to collect data. Five people drove both cars on a prescribed route in Greater Munich (Fig. 10). It involved urban and rural roads as well as highways of equal lengths. In a first step, the logged data with the smallest difference to the average vehicle consumption were chosen for further analysis.

The longitudinal and lateral driving excitation was superimposed with vertical road data. The road profile was generated as described in [18]. For this paper a type ' $B$ ' road [19] was chosen, due to the lack of road quality information in the Munich region. The research of [20] shows that $90 \%$ of the roads in Germany can be assigned to ISO road class A and B. Regarding [21], class B is an appropriate assumption for a bad highway and an average rural road [21] also shows that the road quality has a direct influence on energy losses in dampers. Considering this information, the chosen road quality is a realistic worse case, but lacks a direct link to the driven roads.

As road data input the track-based height of the tire contact points is used. The measured yaw rate and velocity

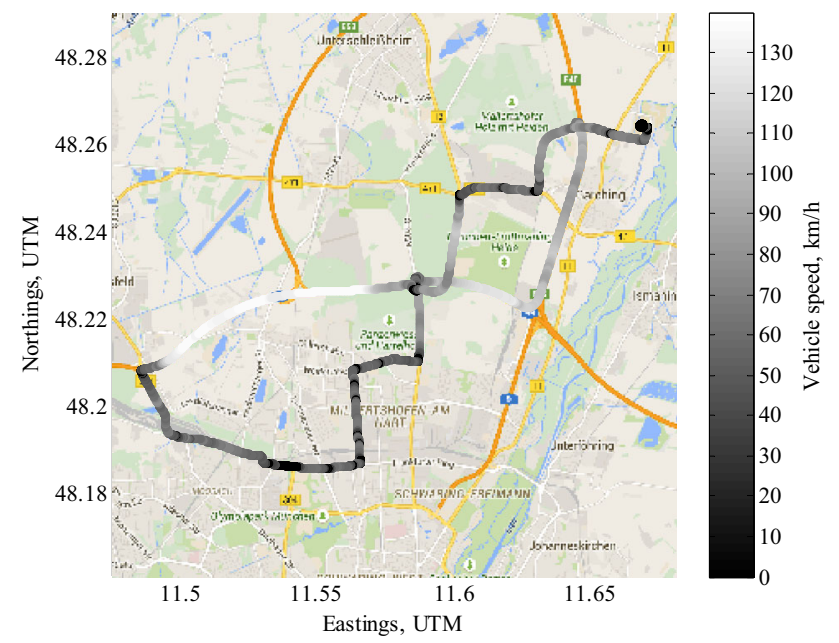

Fig. 10 Route for collecting naturalistic driving behavior
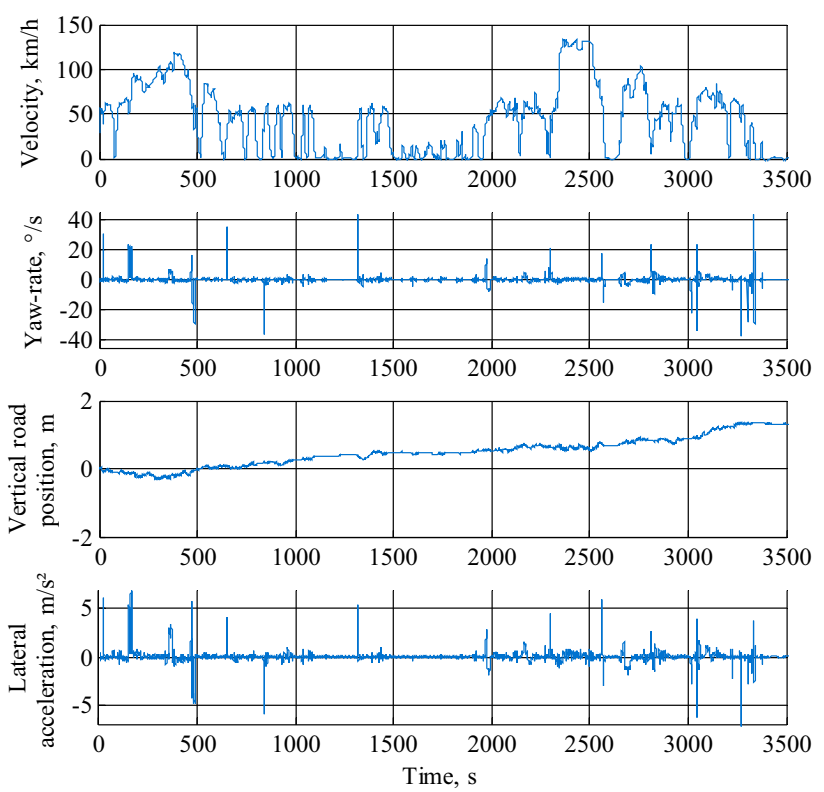

Fig. 11 Consumer relevant model inputs

are used to control the longitudinal and lateral behavior. Those variables explicitly define the driven route, the model inputs are shown in Fig. 11. The resulting additional potential energy, due to increasing elevation of the road is subtracted in the interpretation.

\subsection{Potentials}

Several physical effects of some technologies used for components prevent to save the entire energy losses. For example, the tire needs a side slip angle to transmit lateral forces. This effect always causes energy losses, which can be influenced by tire parameters. Therefore, the evaluation of energy saving potentials is important. The chosen assumptions for identifying the potentials are individual applied to the model.

\subsubsection{Tires}

In case of tires, the consideration is separated into rolling resistance and slip losses. For rolling resistance, tires with a rolling resistance coefficient of 0.004 will be possible in near future. This was simulated by manipulating the rolling resistance factor of the tire parameter file. Looking at the slip losses, the tire model was modified, to meet the stiffness of a tire with the dimension of 335/30R20. Usually this tire is used on high performance vehicles and has a very high cornering stiffness. Due to the effect, that tires need side slip angle to generate lateral forces, the cornering stiffness cannot be infinite. Therefore, the mentioned tire is used as a benchmark for high cornering stiffness. 


\subsubsection{Dampers}

Several concepts to recuperate damper energy can be found in the literature. Most publications lack levels of efficiency or additional weight for the systems. One concept is developed by [22]. The system has an additional mass for the whole car of approximately $\Delta m=16 \mathrm{~kg}$ compared to an adaptive damper, with an assumed extra weight of $\Delta m=4 \mathrm{~kg}$ compared to a conventional one. [22] used a far heavier vehicle for his analysis and system compared to the one in this paper. Therefore, the additional weight is scaled to $\Delta m=10 \mathrm{~kg}$.

Willems [22] does not directly mention the level of efficiency of his system, but it can be calculated from his analysis of the damper energy and translated to $\mathrm{CO}_{2}$ savings. This calculation leads to a level of efficiency of $\eta=77 \%$.

\subsubsection{Wheel bearings}

To optimize the energy losses induced by wheel bearings, there are two possible ways to improve the overall efficiency. One is to optimize the constructive position of the wheel bearings to minimize load on the bearings. The second way is to get a better friction coefficient by optimizing the bearing technology. An improvement of $30 \%$ is assumed in this investigation.

\subsubsection{Drive shafts}

Equivalent to wheel bearings the same two ways can be applied to improve the overall drive shaft efficiency. New technological solutions such as the 'GKN counter track', improve the level of efficiency by approximately $30 \%$ and the mass by $15 \%$. These values are used to identify the potential based on technology improvement.

Technologies like wheel hub motors eliminate drive shafts on one side, but induce numerous secondary effects influencing the chassis concept. This is not taken into consideration here.

\subsubsection{Brake caliper drag}

Brake caliper drag occurs as the play between disk and brake cannot be chosen freely in size for a good response behavior of the brake. An increasing amount of assistance systems integrated in future cars in combination with electromechanical brake systems could make it possible that response behavior might become less important. For this reason, a larger play can be selected and the brake caliper drag could be eliminated. The additional systems in the model weight $25 \mathrm{~kg}$.

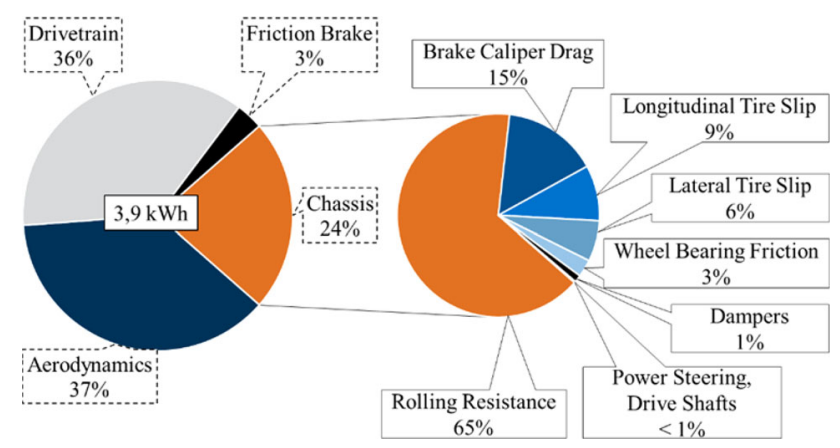

Fig. 12 Distribution of energy losses in vehicle (left) and chassis (right)

\section{Results}

Compared to the vehicle energy consumption in the simulated route, the chassis losses have a $24 \%$ share (Fig. 12). The distribution of the losses in the chassis is shown on the right side. The rolling resistance causes the highest energy losses in the chassis (65\%). The second largest share is caused by the brake caliper drag. Tire slip (lateral and longitudinal) is responsible for $15 \%$ of the lost energy. Wheel bearings, dampers, power steering, and drive shafts make up $5 \%$ in total.

Figure 13 shows the simulated potentials of the components considered in the chassis system. They are split into primary and secondary effects. Primary effects show the variation of the consumption due to the changed parameters of the component model, e.g., a lower rolling resistance coefficient and therefore lower rolling resistance moments. Secondary effects are differences resulting from a changed primary effect. For example, if the rolling resistance is lower, stronger braking is necessary and brake caliper drag increases. The results of the potentials are similar to the loss distributions. In the case of the dampers, a negative overcompensation of the recuperated energy is

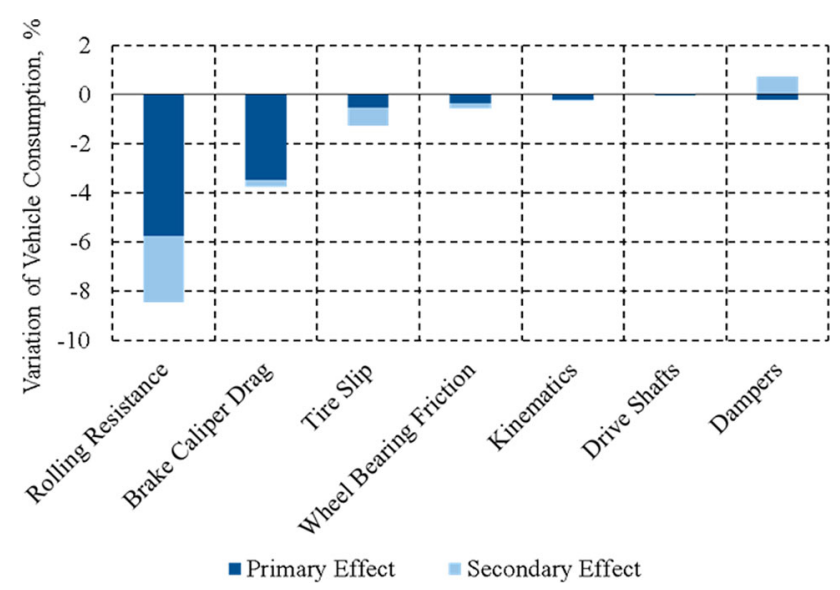

Fig. 13 Results of the simulated potentials to improve energy efficiency 
caused mainly by the heavier car. This leads to a higher vehicle energy consumption level.

The results are an assessment of the energy losses and saving potentials. Thanks to models, that were only verified, the confidence in absolute values is limited, but the distribution shows a profound order for the relevant components.

\section{Discussion}

Based on the state of art, a loss percentage for the whole chassis of 17-21\% was expected. The methods described in this article show a percentage of $24 \%$. The difference to the expected values can be explained by the additional consideration of lateral and vertical dependencies of energy losses. The result of this paper appears plausible for that.

The rolling resistance generates the biggest amount of loss energy in the chassis. Compared to [3], the amount is very similar. The energy losses caused by brake caliper drag are verified thanks to the literature values. Slip losses are comparatively high, due to the low lateral and longitudinal stiffness of the tire model. Wheel bearing friction and losses occurring at drive shafts are similar to the results in [3]. The small amount of damper energy loss is caused by the fairly good road quality. As the damper loss energy is mainly influenced by the tire vertical stiffness [21], the result can also be justified by the low vertical stiffness of the tire $(170 \mathrm{~N} /$ $\mathrm{mm}$ ). Due to the right orders, the result can be used for defining a better degree of abstraction for the described loss model and the effort necessary for parametrization and validation.

Looking at the results regarding energy saving potentials, it is conspicuous, that the distribution is similar to one of the chassis losses. This leads to the assumption that the components' percental potentials are comparable.

The modeled interactions in the full model are working as shown through secondary effects. Dependencies between the sub-models representing the loss effects have to be modeled. To get more precise and absolute values in future research, the driver's behavior will be analyzed using a bigger data pool, which will result in a synthetic driving cycle with longitudinal and lateral dynamics. Also, the vertical impulse will represent the driven road more realistically.

\section{Conclusion}

A method was shown to identify the loss of energy in all chassis systems. To identify the energy saving potential, improvements in technology were analyzed. It was shown, that there is a usable energy saving potential. Nevertheless, the results have limited reliability regarding the absolute values. They will be improved by better model validation, driver behavior and more detailed modeling of component's dependencies in future research.

\section{References}

1. Abadie, V.: Present and future chassis solutions for $\mathrm{CO}_{2}$ emissions reduction. In: Pfeffer, P. (ed.) chassis.tech plus 2012, pp. 5-7. Springer, Wiesbaden (2012)

2. Levander, T.: The relative contributions to the greenhouse effect from the use of different fuels. Atmos Environ 24A(11), 2707-2714 (1990)

3. Heißing, B., Ersoy, M. (eds.): Chassis Handbook. Springer Verlag, Wiesbaden (2011)

4. Vietinghoff, A.: Nichtlineare Regelung von Kraftfahrzeugen in querdynamisch kritischen Fahrsituationen. Universitätsverlag Karlsruhe, Karlsruhe (2008)

5. Pacejka, H.B.: Tire and Vehicle Dynamics, 2nd edn. ButterworthHeinemann, Amsterdam (2009)

6. Bereszewski, M. (ed.): ATZextra: Forschungsprojekt Visio.M. Springer Vieweg, Wiesbaden (2014)

7. International Organization for Standardization: ISO 4138-Passenger cars-Steady-state circular driving behaviour-Open-loop test methods (2004)

8. International Organization for Standardization: ISO 7401-Road vehicles-Lateral transient response test methods-Open-loop test methods (2009)

9. Peckelsen, U., Gauterin, F.: Influence of real operating conditions on total rolling resistance. ATZ Worldw 115(11), 54-59 (2013)

10. Kraus, A.: $\mathrm{T}^{3} \mathrm{M}$-TireEMISSION. In: Ulber, B. (ed.) chassis.tech 2009. ATZlive, Wiesbaden (2009)

11. Unrau, H.-J.; Zamow, J. (eds.): TYDEX-Format-Description and Reference Manual, Release 1.3. TYDEX Workshop, Karlsruhe (1997)

12. Van Putten, B. J. S., Lehmpfuhl, T., Pinnel, A., Chucholowski, C., Rill, G.: A dedicated tire model for simulation of performance and fuel consumption. In: Ulber, B. (ed.) chassis.tech plus 2011, ATZlive, Wiesbaden (2011)

13. SKF: Rolling Bearings. http://www.skf.com/binary/30-121486/ SKF-rolling-bearings-catalogue.pdf(2014). Accessed 1 july 2015

14. Crampen, M., Homann, J., Hagen, D., Biermann, J.-W.: Verlustleistungen von Gelenkwellen und Radnaben einschließlich Bremse, In: Pischinger, S. (ed.) 18. Aachener Kolloquium Fahrzeug- und Motorentechnik. fka Forschungsgesellschaft Kraftfahrwesen mbH, Aachen (2009)

15. Breuer, B., Bill, K.H. (eds.): Brake Technology Handbook. SAE International, Warrendale (2008)

16. Heimann, S. (ed.): Methodische Ansätze zur Untersuchung des Restbremsmomentes von Scheibenbremsen. Digitale Bibliothek Thüringen. Ilmenau Univ.-Bibliothek, Ilmenau (2011)

17. Gaedke, A., Heger, M., Vähning, A.: Electric power steering in all vehicle classes - state of the art. In: Proceedings of 2010 chassis. tech plus, Wiesbaden (2010)

18. Löhe, K., Roppenecker, G., Zehelein, T.: Ein modulares Konzept zur Fahrbahngüteschätzung und Kalman-Filter-Adaption mittels autoregressiver Filterung. In: VDI-Berichte 2233, Düsseldorf (2015)

19. International Organization for Standardization: ISO8606-Mechanical vibration-Road surface profiles-Reporting of measured data, International Organization for Standardization, Genève (1995)

20. Braun, H., Hellenbroich, T.: Meßergebnisse von Straßenunebenheiten. VDI-Berichte 877

21. Willems, M.: Estimation of the recuperation potential of shock absorber energy. ATZ Worldw 114(9), 28-32 (2012)

22. Willems, M.: Chances and concepts for recuperating damper systems. In: Pischinger, S. (ed.) 21st Aachen Colloquium Automobile and Engine Technology, fka Forschungsgesellschaft Kraftfahrwesen mbH, Aachen (2012) 